\title{
A quantitative microbial risk assessment model for Listeria monocytogenes in RTE sandwiches
}

Tirloni, E.; Stella, S.; de Knegt, Leonardo; Gandolfi, G.; Bernardi, C.; Nauta, Maarten

Published in:

Microbial Risk Analysis

Link to article, DOI:

10.1016/j.mran.2018.04.003

Publication date:

2018

Document Version

Peer reviewed version

Link back to DTU Orbit

Citation (APA):

Tirloni, E., Stella, S., de Knegt, L., Gandolfi, G., Bernardi, C., \& Nauta, M. (2018). A quantitative microbial risk assessment model for Listeria monocytogenes in RTE sandwiches. Microbial Risk Analysis, 9, 11-21.

https://doi.org/10.1016/j.mran.2018.04.003

\section{General rights}

Copyright and moral rights for the publications made accessible in the public portal are retained by the authors and/or other copyright owners and it is a condition of accessing publications that users recognise and abide by the legal requirements associated with these rights.

- Users may download and print one copy of any publication from the public portal for the purpose of private study or research.

- You may not further distribute the material or use it for any profit-making activity or commercial gain

- You may freely distribute the URL identifying the publication in the public portal 
A Quantitative Microbial Risk Assessment model for Listeria monocytogenes in RTE sandwiches

E Tirloni, S Stella, L.V. de Knegt, G Gandolfi, C Bernardi, M.J. Nauta

PII:

DOI:

Reference:

To appear in:

Received date:

Revised date:

Accepted date:
S2352-3522(18)30006-9

10.1016/j.mran.2018.04.003

MRAN 54

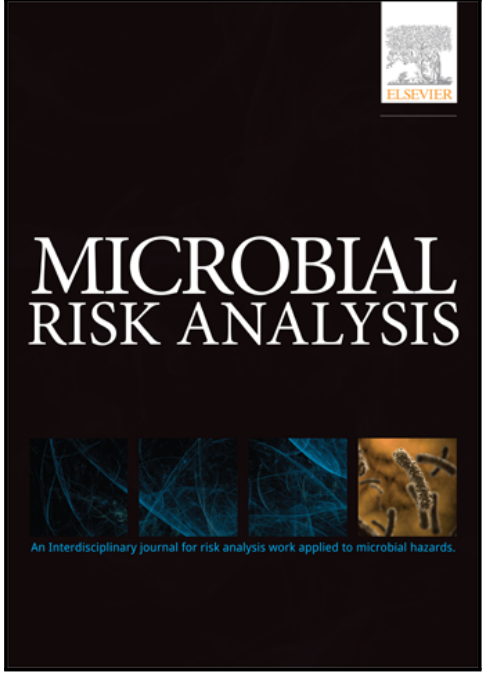

Microbial Risk Analysis

Please cite this article as: E Tirloni , S Stella , L.V. de Knegt, G Gandolfi , C Bernardi , M.J. Nauta , A Quantitative Microbial Risk Assessment model for Listeria monocytogenes in RTE sandwiches, Microbial Risk Analysis (2018), doi: 10.1016/j.mran.2018.04.003

This is a PDF file of an unedited manuscript that has been accepted for publication. As a service to our customers we are providing this early version of the manuscript. The manuscript will undergo copyediting, typesetting, and review of the resulting proof before it is published in its final form. Please note that during the production process errors may be discovered which could affect the content, and all legal disclaimers that apply to the journal pertain. 


\section{A Quantitative Microbial Risk Assessment model for Listeria monocytogenes in RTE sandwiches}

Tirloni E. ${ }^{1}$, Stella S. ${ }^{1}$, de Knegt L.V. ${ }^{2,3}$, Gandolfi G. ${ }^{1}$, Bernardi C. ${ }^{1}$, Nauta M.J. ${ }^{2}$

1 Department of Health, Animal Science and Food Safety, University of Milan, Via Celoria 10, 20133 Milan, Italy

2 Technical University of Denmark, National Food Institute, Research Group for Risk-Benefit, Kemitorvet, Building 201, 2800 Kgs. Lyngby, Denmark.

3 Department of Veterinary and Animal Sciences, Faculty of Health and Medical Sciences, University of Copenhagen, Grønnegårdsvej 8, 1870 Frederiksberg, Denmark.

*Corresponding author. Department of Health, Animal Science and Food Safety, University of Milan, Via Celoria 10, 20133 Milan, Italy. Tel: +390250317855; E-mail address: erica.tirloni@unimi.it (E. Tirloni).

Keywords: QMRA, Listeria monocytogenes, sandwiches, bean cream, cream cheese 


\section{Abstract}

A Quantitative Microbial Risk Assessment (QMRA) was performed to estimate the expected number of listeriosis cases due to the consumption, on the last day of shelf life, of 20000 servings of multi-ingredient sandwiches produced by a medium scale food producer in Italy, by different population strata, defined by infection susceptibility (healthy, susceptible, transplant recipients and total population).

First, all the sandwich ingredients were analysed for $\mathrm{pH}$, Aw, salt and organic acids content and submitted to challenge tests at three different temperatures $\left(4,6\right.$ and $\left.10^{\circ} \mathrm{C}\right)$ to evaluate their suitability for L. monocytogenes growth. Next, a stochastic model was constructed simulating the contamination of the ingredients that were the best (bean cream) and worst (cheese cream) growth substrates. For each substrate, an exposure assessment was performed, estimating the number of L. monocytogenes within each serving. Then, two dose-response models were alternatively applied: the first used a fixed $r$ value for each of the three population groups, while the second considered a variable $r$ value (lognormal distribution), taking into account the variability in strain virulence and different host subpopulations susceptibility.

The stochastic model predicted zero cases for total population for both the substrates by using the fixed $r$ approach, while 3 cases were expected when a higher variability (in virulence and susceptibility) was considered in the model; the number of cases increased to 45-52 in the worst scenario (bean cream contamination) assuming all servings would be consumed by transplant recipients.

An uncertainty analysis was performed by considering alternative scenarios: a higher mean bacterial concentration $(+0.5 \mathrm{Log}$ CFU/g) or higher standard deviation $(+0.5)$ determined evident increases in the expected number of cases, almost doubling the risk. A similar effect was also exerted by an extended storage time (from 72 to $96 \mathrm{~h}$ ), in particular in the worst case scenario. Finally, different protective interventions were evaluated $\left(70 / 30 \mathrm{~N}_{2} / \mathrm{CO}_{2}\right.$ packaging, home cooking or their combination). Both the interventions resulted in a strong decrease of the risk; MAP packaging, should be regarded as the most promising one, as it can be performed by the producer, who can assure a strict control of the treatment performances. 
Listeriosis is a relatively rare foodborne disease with an estimated 2536 confirmed cases in the EU in 2016. At the same time, it raises major concerns, due to high fatality (15-18\%) and hospitalization rates (97-99\%), when compared to other microbial pathogens (EFSA, 2015, 2016, 2017) [1,2,3]. L. monocytogenes is widely distributed in the environment; it is able to grow in a wide range of temperature (from 0 to $45^{\circ} \mathrm{C}$ ) and is resistant to many environmental conditions, such as high salinity or acidity (Walker et al., 1990) [4]. It is frequently isolated in food production and processing plants, and can persist for long periods in foods and food-associated environments (farms, processing plants, retail, and households) (Ferreira et al., 2014) [5]. Although invasive listeriosis can affect healthy subjects, the disease mainly occurs in immunocompromised patients, pregnant women, unborn or newly borns and elderly people. Immunocompromised adults usually experience septicaemia and meningitis, while pregnant women often present non-specific symptoms (e.g. fever and prostration) followed by abortion, stillbirth, premature birth or newly born with bacteraemia and meningitis (Jackson et al., 2010; Silk et al., 2012) [6, 7]. Consumption of contaminated food is by far the main source of transmission, except for newly born, which are contaminated transplacentally, during or after delivery, when the mother is infected. A wide variety of raw and processed foods, including milk and dairy, meat, eggs and their derived products, as well as seafood and vegetables, may be contaminated with L. monocytogenes (EFSA, 2017) [3]. Outbreaks and sporadic cases of listeriosis are predominantly associated with long-shelf-life refrigerated Ready-To-Eat (RTE) foods, as they are intended for consumption without any decontaminating treatment (EFSA, 2017, 2018; Farber and Peterkin, 1991; WHO-FAO, 2004) [3, 8, 9, 10]. A particularly important RTE typology is represented by sandwiches: these foodstuffs are characterized by an intense manipulation during the production process, as well as by the use of different ingredients, which increase the number of potential contamination sources (Cossu et al., 2016) [11]. Various authors have already found L. monocytogenes in sandwiches in different countries such as the United States, United Kingdom, Italy, Algeria, Turkey and South Africa (Bouayad and Hamdi, 2012; Büyükyörük et al., 2014; Christison et al., 2008; Little et al., 2008; Meloni et al., 2009; Shen et al., 2006) [12, 13, 14, 15, 16, 17]. Moreover, several listeriosis outbreaks were reported, especially in nosocomial environments, due to the consumption of contaminated sandwiches purchased from shops or vending machines. Examples of such outbreaks have been frequently reported in the United Kingdom, where eight outbreaks caused by sandwich consumption occurred between 1999 and 2011 (Little et al., 2012) [18].

Quantitative microbial risk assessment (QMRA) is often used to evaluate risks in food safety, as it offers a logical and structured approach to assess risks due to the consumption of a hazard in a specific food. This methodology has been widely applied to several RTE foodstuffs (EFSA, 2018; Carrasco et al., 2010; Matagaras et al., 2010; Nauta et al., 2003) [8, 19, 20, 21]. Although a QMRA-based assessment of Norovirus transmission by multi-ingredient sandwiches has 
already been published (Stals et al., 2015) [22], to the authors knowledge, the same approach has never been specifically applied to L. monocytogenes for this typology of products.

In the present study a stochastic QMRA model for L. monocytogenes was developed. The objective of the model was to estimate the number of cases of listeriosis per year, due to the consumption of RTE sandwiches at the last day of shelf life in different population strata, defined by susceptibility status. Next, different possible interventions were evaluated, to study the potential effect of risk mitigation strategies.

\section{$2 \quad$ Materials and methods}

\subsection{Production of sandwiches}

The product considered was a RTE multi-ingredient sandwich, produced by a medium-scale industry situated in Northern Italy. It contains cold-smoked salmon, cream cheese, bean cream, green salad, raw cut courgettes and bread. For the production, frozen whole pieces of cold-smoked salmon were thawed and cut into slices; pasteurized cream cheese and bread were acquired as pre-packaged ingredients; the fava bean cream was obtained after cooking fava beans in an oven at $100^{\circ} \mathrm{C}$ for 15 minutes, subsequently mixed; RTE salad was used (without a washing step); raw courgettes were washed and cut into julienne strips.

All the ingredients were stored at refrigeration temperatures before the product was assembled by food factory operators wearing mono-use gloves (Figure 1). Each sandwich was cut in two pieces and packaged together in paper/plastic pack (environmental atmosphere), obtaining $210 \mathrm{~g}$ portions (W, weight of the serving, see Table 1). A few hours after packaging, the product was transported at temperatures below $4^{\circ} \mathrm{C}$ to retail shops; a use-by-date of three days was assigned (from the time of production), considering both the retail sale and the home refrigerator. The product is supposed to be stored at temperatures below $4^{\circ} \mathrm{C}$, consumed without the need for heat treatment and does not report any recommendation for sensitive population.

\subsection{Microbiological data}

\subsubsection{Data sources}

Starting concentrations of L. monocytogenes were obtained by analysing a total of 100 samples (packaged sandwich portions) from 25 different batches produced in the selected food industry $\left(\mathrm{N}_{\text {tot }}\right)$. Each batch was constituted of the total daily production. L. monocytogenes was enumerated in the samples within a few hours after the production. For each sample, a representative portion (about half) of the sandwich was mixed, in order to maintain the relative composition of the whole product, and a $10 \mathrm{~g}$ share was taken. The shares were then 10 -fold diluted in pre-chilled sterile saline 
$(0.85 \% \mathrm{NaCl}$ and $0.1 \%$ peptone) and homogenized for 60 seconds in a Stomacher 400 (Seward Medical, London, UK). Further appropriate 10-fold dilutions of the homogenates were made with pre-chilled sterile saline. L. monocytogenes was enumerated by spread plating on Rapid L'mono agar (Generon, Modena, I) and incubated at $37^{\circ} \mathrm{C}$ for $48 \mathrm{~h}$ (AFNOR BRD 07/05-09/01) [23]; detection limit was $10 \mathrm{CFU/g.}$

\subsubsection{Microbiological and physical-chemical characterization of sandwich ingredients}

For the characterization of the sandwich as potential growth substrate, each of the ingredients (bread, salmon, bean cream, cream cheese, courgettes and green salad) was considered separately, as in the final product they are not mixed, but assembled by hand. During five different production days, a sample of each ingredient was transported under refrigeration for microbiological analyses. Briefly, $10 \mathrm{~g}$ of each ingredient were 10-fold diluted in pre-chilled sterile saline and homogenized for $60 \mathrm{~s}$ in a Stomacher 400 (Seward Medical, Worthing, UK). Appropriate 10-fold dilutions of the homogenates were made with pre-chilled sterile saline. L. monocytogenes was enumerated by spread plating onto Rapid L'mono agar (Generon) as described before.

Afterwards, in order to evaluate the environmental permissiveness to the bacterial growth supplied by each ingredient, each component was characterized from a physical-chemical point of view: moisture (Bradley and Vanderwarn, 2001) [24], water activity $\left(\mathrm{a}_{\mathrm{w}}\right)$ (Rotronic Hygromer Aw-DIO, Basserdorf, $\mathrm{CH}$ ), pH (Amel Instrument, 334-B, Milan, I) and salt content (Pearson, 1973) [25] were determined. Concentrations of organic acids were determined by HPLC (Tormo et al., 2004) [26]. Briefly, $1.0 \mathrm{~g}$ of each ingredient was diluted to $5.0 \mathrm{ml}$ in water and vigorously shaken by using a vortex during $20 \mathrm{~s}$. After centrifugation $(3000 \mathrm{x} \mathrm{g} ; 15 \mathrm{~min}$ ) the supernatant was filtered through a $0.45 \mu \mathrm{m}$ cellulose membrane. The HPLC system consisted of two pumps (Waters 510, Milan, Italy), an auto-sampler (Waters 717 plus) and a UV-VIS detector (Waters 484) set at $210 \mathrm{~nm}$. The separation was performed on a Rezex ROA column $300 \mathrm{~mm} \mathrm{x}$ $7.8 \mathrm{~mm}, 8 \mu \mathrm{m}$ (Phenomenex, Torrance, USA). The mobile phase $\left(0.5 \mathrm{ml} \mathrm{min}^{-1}\right.$ in isocratic mode) was $0.005 \mathrm{~N}$ sulphuric acid. External standards were used for identification and quantification of acetic, citric and lactic acids. The limit of detection (LOD: 0.076, 0.23 and $0.24 \mathrm{mM}$ for acetic, citric and lactic acid respectively) and limit of quantification (LOQ: $0.39,0.43$ and $0.77 \mathrm{mM}$ for acetic, lactic and citric acid respectively) were determined. LOD and LOQ were calculated by the signal-to-noise approach (ICH, 1995) [27].

\subsubsection{Growth potential of sandwich ingredients}

Available predictive microbiology software (combase and FSSP) were considered to estimate growth potential of $L$. monocytogenes in each ingredient of the sandwich. As the validation range and the applicability of these software was not always appropriate for each ingredient considered, a series of challenge tests were carried out to determine whether 
L. monocytogenes could grow in each of the ingredients of the sandwich. As raw courgettes and green salad were comparable for physical-chemical characteristics, courgettes were taken as the model for the category called "raw vegetable" for subsequent challenge tests. Growth of L. monocytogenes was determined in 30 independent challenge tests, 6 for each selected ingredient applying three constant storage temperatures $\left(4,6\right.$ and $10^{\circ} \mathrm{C}$ in duplicate). The ingredients, obtained the same day of the sandwich production, were inoculated with two L. monocytogenes strains, previously isolated and identified from the sandwiches (strain LMS45) and from the environment of the production plant (LMS6). The strain stocks were kept frozen at $-80^{\circ} \mathrm{C}$ in Microbank Cryogenic vials (Pro-Lab Diagnostics U.K., Merseyside, UK). From each stock culture, a loop was transferred to Brain Heart Infusion broth (BHI) (Oxoid, Basingstoke, UK) and incubated at $37^{\circ} \mathrm{C}$ for $24 \mathrm{~h}$. Cultures were then re-inoculated in $\mathrm{BHI}$ broth and incubated at $8^{\circ} \mathrm{C}$ in order to pre-adapt the bacteria to the environmental conditions. The cultures were harvested in late exponential growth phase, defined as a relative change in absorbance of 0.05-0.2 at $540 \mathrm{~nm}$ (Jenway 6105, Staffordshire, UK). Cell concentrations were determined by microscopy at 1000x magnification (Motic, B310, Wetzlar, Germany). Finally, precultures of individual isolates were diluted in sterile saline water $(0.85 \% \mathrm{NaCl})$ to obtain the same initial concentration of $2 \log$ CFU g ${ }^{-1}$ after inoculation of the ingredients. To minimize changes in substrate characteristics, the inoculum volume did not exceed $1 \%$ of the weight of the samples. The inoculated ingredients were then incubated at the three temperature conditions reported above. At T0, day of inoculation and after $72 \mathrm{~h}$ (end of the declared assigned shelf-life of sandwiches), samples of each ingredient were submitted to L. monocytogenes enumeration onto Rapid L'mono.

\subsection{Risk assessment}

\subsubsection{Description of the risk assessment model}

A stochastic QMRA model was developed using the Modular Process Risk Model (MPRM) methodology (Nauta, 2008)

[28], to estimate the number of listeriosis cases due to the consumption of 20.000 multi-ingredient sandwiches (each sandwich as a single serving), representing the total annual production amount of a medium scale factory. Starting from the L. monocytogenes prevalence and count data on whole packed sandwiches obtained from the analyses performed on the product, the model focused on the retail/home storage phase, considering the consumption at the last day of shelf life by different populations with specific susceptibility to the pathogen: healthy, susceptible and transplant recipients, and a theoretical total population.

For the baseline scenario, only bacterial growth was modelled, resulting in an eventual change in bacterial concentration without changes in prevalence as, no cross-contamination (pre-packaged product) or inactivation (ready to eat foodstuff) could reasonably occur. 


\subsubsection{Exposure assessment}

Prevalence $(\mathrm{P})$ and L. monocytogenes enumerations $\left(\mathrm{C}_{\text {mean, } \mathrm{SD}}\right)$ of contaminated sandwiches were obtained as described in section 2.2.1. The data obtained were incorporated in a model (Table 1), built in Microsoft Excel with add on @ Risk 7.0.1 (Palisade) for Monte Carlo simulation; 100000 random iterations were run in Excel. The initial bacterial concentration $\left(\mathrm{C}_{0}\right.$ in $\left.\log \mathrm{CFU} / \mathrm{g}\right)$ was described by a Normal Distribution, derived from the data (see the results section).

The increases in bacterial concentration $(\Delta \mathrm{C}$ in $\log \mathrm{CFU})$ after $72 \mathrm{~h}$ storage at different temperatures $\left(4,6\right.$, and $\left.10^{\circ} \mathrm{C}\right)$ were obtained from the challenge tests described in section 2.2.3. We chose the worst case scenario possible, that was the consumption of the sandwiches at the last day of assigned shelf-life. The values considered $($ Temp stor $) \mathrm{were}^{\mathrm{a}}$ minimum temperature of $4^{\circ} \mathrm{C}$ (optimal storage condition), a most likely temperature of $6^{\circ} \mathrm{C}$ (Roccato et al., 2017) [29], and a maximum temperature of $10^{\circ} \mathrm{C}$, which could happen due to an improper home storage in the range $8-10^{\circ} \mathrm{C}(\mathrm{James}$ et al., 2008) [30]. For the subsequent development of the stochastic model, the two ingredients of the sandwich that were the most conducive (highest $\Delta \mathrm{C}$ obtained) and the least permissive (lowest $\Delta \mathrm{C}$ ) for L. monocytogenes growth were considered, in order to cover the whole potential growth range. The substrates were chosen without taking into account the observed prevalence of the pathogen, because the contamination appeared to be linked to the final manipulation of the ingredients rather than to different raw materials (thus no substrates could be considered as surely Listeria-free), and the assembly likely resulted in a contamination of all the ingredients.

The mean of the two $\Delta \mathrm{C}$ values obtained for the two selected ingredients (after 72 hours) were included as a Triangular distribution to describe the variability in the increase of concentration due to growth at different storage temperatures. The final concentration in the product after 72 hours was $\mathrm{C}_{\text {final }}=\mathrm{C}_{0}+\Delta \mathrm{C} \log \mathrm{CFU} / \mathrm{g}$, and the ingested dose $\mathrm{D}=$ $10^{\mathrm{Cfinal}} * \mathrm{~W}$ CFU per serving, for each of the two ingredients.

\subsubsection{Stochastic dose-response model- Part 1}

An exponential dose-response model was applied to each scenario (Equation 1),

$$
\mathrm{P}_{\mathrm{ill}}(\mathrm{D} ; \mathrm{r})=1-e^{-r \times D}
$$

Equation (1)

where $\mathrm{D}$ represents the ingested dose and $r$ is the dose response parameter, representing the probability of illness per cfu (Table 2). Three different $r$ values were considered: $r=2.37 * 10^{-14}$ for the healthy population and $r=1.06^{*} 10^{-12}$ for the susceptible population as suggested by FAO-WHO (2004) [31]; $r=5.8 * 10^{-10}$ was used for transplant recipients (FAOWHO, 2004) [31]. In this dose-response model, these values of $r$ indicate the probability that a single bacterial cell causes listeriosis. 
To obtain the expected number of cases, the mean $\mathrm{P}_{\text {ill }}$ of 100.000 model iterations was multiplied with the number of servings $\left(\mathrm{N}_{\mathrm{s}}\right)$ produced by the food industry every year (20.000) and with the prevalence of contaminated samples detected in the first phase of the study (see section 2.1). Finally, the expected number of cases in the theoretical total population was calculated, assuming that $23 \%$ of the total population consists of susceptible people (pregnant, old $>65$ years, children, immunocompromised, etc.), as shown in a similar situation in France by Pouillot et al. (2015) [32], but adjusting the percentage of transplant recipients to $0.0062 \%$ (about one person per 20.000 consumers), based on the Italian available data (Ministero della Salute, 2017) [33].

\subsubsection{Stochastic dose-response model- Part 2}

Another exponential dose-response model was applied to each scenario (Equation 1, section 2.3.3). As suggested by Pouillot et al., (2015) [32], a lognormal-Poisson distribution of $r$ was used to take the variability in strain virulence and host susceptibility for healthy and transplanted populations into account (Table 2). Such approach has been recently applied by EFSA BIOHAZ panel to estimate the risk for EU population in consuming RTE foods (EFSA, 2018) [8]. For the susceptible population, that is composed by various subpopulations with different susceptibility (Pouillot et al., 2015) [32], a representative $r$ value was obtained from a discrete distribution of the $r$ values (lognormal distributions) of the specific subpopulations (people > 65 years, pregnant women, people affected by diabetes, renal failure, cancer, etc.) weighed by the relative size of these subpopulations. As described in the previous section, the relative composition of the susceptible population reported by Pouillot et al. was corrected based on the different rate of transplanted Italian people. Finally, the mean $\mathrm{P}_{\text {ill }}$ was obtained performing 1.000 .000 model iterations.

\subsubsection{Uncertainty in the risk assessment model}

Uncertainties in the risk assessment model were studied by scenario analyses (Table 3). The uncertainties considered were:

a) Prevalence of contaminated samples.

Uncertainty in prevalence can be expressed by a distribution $\left(\mathrm{P}_{\text {stoc }}\right)$, defined as Beta $(\mathrm{s}+1, \mathrm{n}-\mathrm{s}+1)$ where $\mathrm{n}$ is the number of samples and $\mathrm{s}$ is the number of positive samples. As scenarios we analysed the 1, 5, 10, 90, 95 and $99 \%$ percentiles of this distribution.

b) Sample bacterial concentrations. To consider the uncertainty in bacterial concentration assessment, two alternative scenarios were taken into account: a $0.5 \mathrm{Log}$ CFU/g higher mean concentration $\left(\right.$ HighC $\left._{\text {mean }}\right)$ and a $0.5 \mathrm{Log} \mathrm{CFU} / \mathrm{g}$ higher standard deviation $\left(\right.$ HighC $\left._{\mathrm{SD}}\right)$. 
c) Storage duration: a higher storage duration, simulating the consumption one day after the use-by-date assigned (96 h), was considered $(96 \mathrm{~h} \Delta \mathrm{C})$. A series of challenge tests was carried out in the two components of the final product selected as described in section 2.3.2. Challenge tests were performed as described in section 2.2.3. Growth of $L$. monocytogenes was determined in 12 independent challenge tests, 4 for each of the two component at constant storage temperatures $\left(4,6\right.$ and $\left.10^{\circ} \mathrm{C}\right)$. L. monocytogenes was enumerated at the day of inoculation, and after $96 \mathrm{~h}$. Mean $\Delta \mathrm{C}$ at the three different temperatures were obtained, and used in the exposure assessment model.

The models were then applied as described in sections 2.3.2, 2.3.3 and 2.3.4. The expected number of cases calculated for each scenario were used to calculate the Relative Risk (Equation 2) which facilitates the comparison of the results of the different scenarios with those obtained with the baseline scenario.

Relative Risk $=$ cases predicted in the new scenario/cases predicted in the baseline

Equation (2)

\subsubsection{Evaluation of possible interventions}

The effects of three different interventions were considered (Table 3):

a) Addition of Modified Atmosphere Packaging (MAP) at the end of the production process;

b) Household heat treatment before consumption;

c) Combination of these two interventions.

To evaluate the effect of MAP, a series of challenge tests was carried out for the two ingredients selected, as described in section 2.3. Challenge tests were performed as described in section 2.2.3. After inoculation, each ingredient was packaged with an artificial atmosphere composed by $30 \% \mathrm{CO}_{2}$ (maximum level above which modification in the texture of food product could be revealed by the consumer) and $70 \% \mathrm{~N}_{2}$. Afterwards, growth of L. monocytogenes was determined in 12 independent challenge tests, six for each of the two components at constant storage temperatures $(4,6$ and $10^{\circ} \mathrm{C}$ ). L. monocytogenes was enumerated as described above at T0 (day of inoculation), and after $72 \mathrm{~h}$. Mean MAP $\triangle \mathrm{C}$ values $\left(\log _{\text {J }} \mathrm{CFU} / \mathrm{g}\right)$ were calculated and inserted in the Triangular distribution (see section 2.3.2) Next, the expected numbers of cases were estimated by Monte Carlo simulation, as in the baseline scenario.

To evaluate the effect of a heat treatment, the potential decrease in log concentration was considered. Decimal reduction times $\left(\mathrm{D}_{\text {temp }}\right)$ for L. monocytogenes for temperatures between 58 and $66^{\circ} \mathrm{C}$ were obtained from the literature (Shi et al., 2015, data obtained in cold smoked salmon) [34]: an average of three values (from different strains) for each of the five temperatures was used (Table 4). In the stochastic model, these five values were sampled with equal probability (using the Duniform distribution in @Risk), obtaining an estimated D-value $\left(D_{\text {val }}\right)$. The cooking time was described as a triangular distribution assuming a minimum cooking time of $1 \mathrm{~min}$, a most likely of 3 min and a maximum of 4 min. 
The reduction in concentration was calculated as $\operatorname{Cook} \Delta \mathrm{C}=\mathrm{Time} / \mathrm{D}_{\mathrm{val}}$ and used to calculate the dose after inactivation $\left(\right.$ CookC $\left.\mathrm{final}_{1}\right)$; the dose-response model was applied as described for the baseline scenario (section 2.3.3 and 2.3.4).

\section{$3 \quad$ Results}

\subsection{Contamination of sandwiches and ingredients}

A total of 43 sandwich samples out of 100 analysed were found to be contaminated by L. monocytogenes (i.e., a prevalence of 0.43 ) with loads ranging from 1.00 (limit of detection) to $2.87 \mathrm{Log}$ CFU/g (mean value 1.54, standard deviation 0.50 with $18.6 \%$ of samples showing values $>2 \log$ CFU/g). This result showed a very high spread of the pathogen in this product, when compared with results obtained by other authors on similar product typology in Italy (Meloni et al., 2009) [16] or in other areas. Our data may indicate a probable contamination source deriving from the raw material and/or an eventual colonization of the production line, contaminating the end product. This was confirmed from prevalences of the single ingredients as reported below in this section.

The presence of L. monocytogenes in raw materials can be considered natural, particularly for cold-smoked salmon (presence was found up to $26 \%$ in a previous study by Rørvik et al., 1994) [35] and raw vegetables (Lokerse et al., 2016; Mena et al., 2004) [36, 37]. In our study, none of the five cold-smoked salmon, green salad and courgettes samples showed loads of the pathogen above the detection limit (1 Log CFU/g). The same was observed for bread, as this ingredient is heat treated and sealed, and so it is not generally considered a potential contamination source. Cream cheese seems not to be relevant as a source of contamination; in a previous study, only $1.9 \%$ of 108 Italian cream cheese samples were contaminated with L. monocytogenes (Di Pinto et al., 2010) [38]. Moreover, in our case, only prepackaged, pasteurized cream cheese was used, thus contamination likely occurs as a consequence of contamination during the sandwich manufacturing process. As for the bean cream, L. monocytogenes was detected in two out of the five samples (mean value 3.24 $\mathrm{Log} \mathrm{CFU} / \mathrm{g}$ ). This result was unexpected, due to the heat treatment applied during the preparation of the cream; thus, in order to better understand if this ingredient could be the main source of contamination, nine extra samples of bean cream, obtained from nine different batches, were analysed. $L$. monocytogenes was present in three out of nine samples, with loads equal to 1.00, 1.90 and 3.27 Log CFU/g (LOD = 1 Log CFU/g), confirming the critical role of this ingredient in the production process.

\subsection{Characterization of sandwich ingredients as potential growth substrates}

The results of the physical-chemical characterization of each ingredient of the sandwiches are summarized in Table 2. Based on Aw, pH, moisture and salt concentration values, all the ingredients but bread and cream cheese were considered good substrates for the growth of L. monocytogenes. Courgettes, green salad, bean cream and cold smoked 
salmon showed high aw and moisture, a pH close to neutrality and percentages of salt very far from those able to inhibit this pathogen. Bread and cream cheese were considered less permissive for the growth, due to low pH, (in particular cream cheese). Considering organic acid determination, acetic and lactic acids were already described, when present in significant amounts, as inhibitors of bacterial population (Friedrich et al., 2008; Stella et al., 2015) [39, 40]. Cream cheese, in particular, contained the highest level of lactic acid and a considerable amount of acetic acid (Table 5). Also salmon and courgettes contained amounts of lactic and a small amount of acetic acid, while green salad contained only acetic acid. Finally, bread and bean cream resulted to contain small amount of lactic and acetic acid (bread in particular showed just traces). The presence of citric acid was detected in some of the ingredients, but this compound has already shown a weak effect on L. monocytogenes growth also at concentrations strongly higher than those observed in our samples.

The challenge tests performed on the ingredients highlighted bean cream as the best substrate for the growth of $L$. monocytogenes, and cream cheese as the worst one, at any temperature of storage considered (Table 6). The observed growth potential was always larger than those obtained by the predictive modelling software applied (data not shown). These results could be due to the need for a wider range of applicability (e.g. low pH or salt content for FSSP) or a more complete set of parameters (such as organic acids and food matrix characteristics, for Combase), to represent a complex substrate.

These two ingredients were subsequently considered for the development of two models to estimate the expected number of cases, if the pathogen was present in bean cream, thus mimicking the most probable contamination in the process analysed ("worst case scenario"), and in the opposite case, if the pathogen was present in the ingredient with the less permissive environmental parameters for its growth ("best case scenario"). Based on these results, in the baseline scenario, the increase in concentration was described by Triangular distributions Triang $(2.10,2.88,3.85)$ (bean cream) and Triang $(0.59,0.62,0.63)$ cream cheese.

\subsection{Risk assessment model}

Two models were developed with each of the two approaches considered (fixed and variable $r$ values) allowing to assess the growth of L. monocytogenes in two ingredients that differently support its growth (bean cream and cream cheese). With the first approach (fixed $\mathrm{r}$ values), the results showed the absence of expected cases resulting from the consumption of 20.000 servings, all eaten by healthy or susceptible people, in both the best and the worst case scenario (Table 7). In a hypothetic consumption of all the 20.000 portions by transplanted (extremely susceptible) people, no cases were expected with the best scenario (cream cheese) (expected cases: 0.286), while 52 listeriosis cases should be 
expected in the worst one (bean cream). In the last situation, a percentage of $0.26 \%$ transplant recipients would become ill (one case/385 transplanted consumers per consumed sandwich).

Transplant recipients represent only $0.0062 \%$ of the whole population, corresponding to one subject in a randomized population of 20.000 people, while susceptible people correspond to $23 \%$ (corresponding to 4657 subjects). Thus, less than one expected case per year was obtained in the two baseline scenarios considered, even if these results should be carefully reflected, especially if an increase in total servings occurs, leading to a higher number of people with an immunocompromised system being exposed to this hazard. As stated by EFSA (2018), the proportion of susceptible people (especially within the elderly population) is one of the main risk factors for human listeriosis [8].

Considering the second approach (with variable $r$ values), three expected cases resulted in the total population from the consumption of 20.000 servings, in the worst case scenario (bean cream contaminated) while no cases were estimated in the best case scenario (cream cheese contaminated) (Table 8). In a hypothetic consumption of all the 20.000 portions by transplanted people, differently from what found with the model that considered fixed values of r, one case resulted also from the best case scenario (cream cheese), while 45 listeriosis cases should be expected in the worst one (bean cream).

\subsection{Evaluation of uncertainties in the stochastic models}

Different uncertainties present in the developed stochastic model were evaluated for both the approaches by the construction of various scenarios (Tables 7 and 8 ).

First, risk estimates were obtained for different percentiles of the Beta distribution describing the uncertainty in prevalence. As shown in table 4, no cases were obtained with both the best case and worst case models applied to the total population, even considering the $99^{\text {th }}$ percentile of the uncertainty distribution of the prevalence. The same was obtained with a population consisting of healthy or susceptible people only, meaning that, in these populations prevalence does not greatly affect the uncertainties of the stochastic models. As expected, if all the 20.000 servings were consumed by transplant recipients, as the prevalence percentile increased, also the number of expected cases raised gradually in the worst case scenario (bean cream contaminated). The supposed exclusive contamination of cream cheese resulted in an imperceptible increase of expected cases, that were again $<1$. Considering a higher mean bacterial concentration or higher standard deviation $(+0.5 \mathrm{Log} \mathrm{CFU} / \mathrm{g})$, an increase in expected cases occurred in both the scenarios; in particular, with cream cheese one and two cases if the population was completely constituted by susceptible or transplant recipients, would occur respectively. In bean cream, this source of uncertainty in the same category of people would result in a large increase in the number of case (from 52 to 156 and 210 cases, respectively). 
The other source of uncertainty considered was the storage time, as the expiry date may not be respected by the consumers. As expected, a $24 \mathrm{~h}$ increase of storage time increased the risk. Still, due to the low risk level, no cases were expected for healthy or susceptible people in the worst scenario (bean cream), nor in the total population, also if an evident increase was obtained (from 0.028 to 0.082 cases). The expected number of cases remained $<0.0001$ in the best case scenario (cream cheese). In the hypothetical case of the consumption of all the 20.000 sandwiches by transplant recipients, the $96 \mathrm{~h}$ storage resulted in a high number of expected cases in the worst case scenario (+ 99 cases), while in the best scenario the longer storage time still did not result in one or more expected cases.

An overview of the results of the uncertainty analysis is given by the Log Relative Risk calculated for transplanted people only, which illustrates how the different scenarios are related to the baseline in bean cream $(\log R R=0)$. The uncertainties related to the storage time and bacterial counts (mean and standard dev) had the largest impact on the expected number of cases, especially the standard deviation. The log Relative Risk values obtained in the total population were equal to 0.48 and 0.60 for increased mean concentration and increase in standard deviation, respectively, representing approximately a threefold and sevenfold increase of the risk.

By applying the lognormal-Poisson extension of the exponential dose-response model, no cases were obtained with the best case scenario (cream cheese) applied to the total population, even considering the $99^{\text {th }}$ percentile of the uncertainty distribution of the prevalence. The same was obtained with a population consisting of healthy or susceptible people only, while if all the 20.000 servings were consumed by transplant recipients, a case was reported and confirmed for each prevalence considered.

A different result was obtained for the worst case scenario (bean cream) where the number of expected cases raised gradually in susceptible, transplanted and total population. Considering a higher mean bacterial concentration or higher standard deviation (+0.5 Log CFU/g), with this model, an increase in expected cases occurred in both the scenarios. As already reported for the previous model, a $24 \mathrm{~h}$ increase of storage time increased also the risk especially in susceptible, transplanted and total population if considering bean cream contaminated (Log relative risk in total population equal to 0.37). In the hypothetical case of the consumption of all the 20.000 sandwiches by transplant recipients, the $96 \mathrm{~h}$ storage resulted in a high number of expected cases in the worst case scenario ( +56 cases), while in the best scenario the longer storage time did not result in an increase of the cases that was expected in the baseline.

The $\log$ Relative Risk values obtained in the total population were equal to 0.30 and 0.37 for increased mean concentration and increase in standard deviation, respectively, representing approximately a doubling of the risk.

\subsection{Evaluation of possible interventions}


Considering the model developed with fixed $r$ values, as less than 0.5 case is expected for bean cream and cream cheese for all populations, except for the transplant recipients in the bean cream scenario (Table 9), only the last case was considered. Here, a reduction by the application of the interventions would be evidently realized. In particular, by applying the MAP conditioning $\left(30 \% \mathrm{CO}_{2}\right)$, a reduction of $69.8 \%$ in expected number of cases would be obtained, while by applying the thermal treatment, a reduction of $79.2 \%$ would be gained. Such a heat treatment could be feasible, as it is a regular habit of Italian consumers. The combination of the two interventions would allow to reduce the number of cases by $94.3 \%$, thus leaving just 3 cases of the 52 expected in the baseline. This result is also presented for the log Relative Risk showing the major role of cooking in the reduction of expected cases: the log Relative Risk values obtained were equal to $-0.52,-0.68$ and -1.25 for MAP packaging, cooking or their combination, respectively.

Considering the model developed with variable $\mathrm{r}$ values, in cream cheese less than 0.5 case was expected for all populations, except for the transplant recipients (1 case) (Table 10). Only the last case was considered when the effects of interventions were evaluated. Here, a reduction by the application of the interventions would be evidently realized. In particular, by applying the MAP conditioning $\left(30 \% \mathrm{CO}_{2}\right)$, or the thermal treatment, or the combination of the two interventions a reduction from 1 to 0 case was always obtained. In bean cream, as almost 1 case was expected in healthy, susceptible, transplant and total population, all these categories were considered in terms of effect of possible interventions. For all categories a reduction by the application of the interventions would be evidently realized. In particular, by applying the MAP conditioning $\left(30 \% \mathrm{CO}_{2}\right)$, a reduction of $78 \%, 55.5 \%, 51.1 \%$ and $66.7 \%$ in healthy, susceptible, transplant and total population in expected number of cases would be obtained respectively. By applying the thermal treatment, a reduction of $87.8 \%, 66.7 \%, 73.3 \%$ and $66.7 \%$ in healthy, susceptible, transplant and total population in expected number of cases would be obtained respectively. Finally, a greater reduction $(96.1 \%, 88.9 \%$, $86.7 \%$ and $90.4 \%$ in healthy, susceptible, transplant and total population) would be obtained in all the subcategories of the population by the combination of the two interventions.

This result was also/presented for the log Relative Risk (Figure 2) in total population, illustrating the major role of cooking in the reduction of expected cases: the log Relative Risk values obtained were equal to $-1.53,-1.81$ and -2.18 for MAP packaging, cooking or their combination, respectively.

\section{Discussion and conclusion}

In the present work, the risk of listeriosis due to the consumption of 20.000 servings of RTE multi-ingredient sandwiches, based on data and assumptions, was estimated. Quantitative MRA can simulate the effect of consumer exposure to a specific hazard in a food system and the resulting risk for the population. In this case, the individual 
difference in susceptibility (healthy, susceptible or transplanted) was included by applying different $r$ values in the doseresponse relation through two approaches: in the first one by using fixed values of $\mathrm{r}$ (WHO/FAO, 2004), in the second one by using a distribution of $\mathrm{r}$ values (Pouillot et al., 2015) [32]. The approaches were then compared, enabling an estimation of the expected number of cases for the total population or for subpopulations with different susceptibility.

In our stochastic baseline model obtained using fixed values of $r$, no listeriosis cases were estimated for the annual production of a medium scale factory in the total population considering the contamination of the least permissive ingredient or the most permissive one. The destination of this product typology requires a particular care, as the potential use for mostly susceptible consumers can cause concerns. In previous years, RTE foods were responsible for outbreaks involving up to 12 cases in Italy [41]. In the case studied, in a hypothetical population consisting only of transplant recipients, the number of expected cases estimated would be 52 in the "bean cream" scenario. This value should be carefully considered, also according to the several listeriosis occurred in nosocomial patients, that consumed contaminated RTE sandwiches sold in vending machines in hospitals (Little et al., 2012) [18].

With the second approach considered, where $r$ was described by a distribution, the model included the variability in strain virulence across population subgroups, reaching a more accurate and precise estimation of cases,

In particular this second approach included the risk in the subgroup of population with highest risk of listeriosis: this was clearly evidenced by an increase in case number in susceptible subpopulation (from 0 to 9 cases in baseline if bean cream was contaminated) if compared to the approach that used fixed $r$ values. Such difference can be attributed to the role of certain rare but relevant events, such as the ingestion of highly virulent strains by highly susceptible individuals, that can be better highlighted by a more stochastic approach. As a matter of fact, the "susceptible population" described by Pouillot et al. (2015) [32] includes also some small groups of people (e.g. affected by haematological cancer) whose susceptibility can be hardly described by a fixed $r$ value for YOPI population.

The contamination patterns for multi-ingredient sandwiches are complex, as L. monocytogenes is ubiquitous and different ingredients are known to be a potential source of the pathogen (e.g. cold smoked salmon, courgettes, bean cream etc.), and cross contamination between contaminated ingredients with other components or from improperly sanitized containers/utensils to ingredients could occur and should be considered as a constant concern. Anyway, it is likely that in the whole product Listeria would be distributed in the different "layers" of the sandwich, thus enabling to consider also a scenario that is close to the worst one.

In addition, some other factors must be taken into account, like the personnel hygiene and the management of structures and equipment: such contamination ways can affect all the substrates, both the naturally contaminated (as 
vegetables) and the ingredients that should be free from the pathogen due to their production process (such as bean cream). Moreover, the probability of previous presence of Listeria in the ingredients depends on their production/packaging process: for example, the contamination of cream cheese is a very unlikely event, as it is acquired by the sandwich producer as pasteurized pre-packaged foodstuff, and each pack is opened only at the moment of sandwiches preparation, while bean cream is prepared, cooked and stored in the sandwich production plant, so being potentially prone to environmental contamination sources.

The substrates for the simulations were chosen in order to set a "minimum-maximum range": an evident difference among the two ingredients was shown, in particular likely thanks to the effect of physical-chemical characteristics of substrate (e.g. pH, organic acids, moisture).

Different scenarios were also studied in order to include uncertainties in the model, such as the prevalence of contaminated food units, the mean value and variability of bacterial counts in the contaminated samples and the storage time. From the results it was clear that the uncertainties that mainly affect the estimated number of cases were related to the mean and the variability of the L. monocytogenes counts among the contaminated units. These findings stress the impact of the consumption of heavily contaminated samples rather than a frequent contact with low numbers of the pathogen in determining Listeria infection. Hence, as the presence of the pathogen in the raw materials sometimes could be hardly avoided by the sandwiches producer, any effort should be made to improve factory hygiene during production and, although this, a presence of the pathogen occurs, to prevent growth of Listeria in the product. The prevalence of contaminated food units should be considered as another source of uncertainty, particularly for this type of product. In fact, sandwiches production is characterized by the use of many different ingredients (and consequently among lots) and by a strong intervention of the operator, thus being influenced by the individual hygienic behaviours.

Also the number of servings is an important information to consider: if an increase up to 1.000 .000 of servings was reached by producing factory, the number of estimated cases obviously would raise: for instance, in the worst case scenario (bean cream) in the total population (data not shown in table), 135 expected cases would be obtained. Although the number of people infected, the rate of infection would be equal independently from the number of servings $(0.015 \%$ and $0.014 \%$ with 20.000 and 1.000 .000 servings respectively).

Finally, a potential effect of an increased storage duration was observed: with the first approach (fixed $r$ values), although less than one expected case was obtained in the total population in both the scenarios, an evident impact was exerted in the case of a population completely composed by transplant recipients. With the second approach an important increase in case number in total population was evidence (from 3 to 7 ), if the product would be consumed 24 $\mathrm{h}$ after the shelf-life. This factor has to be carefully taken into account. From a regulatory point of view, as the product 
declared shelf life is less than five days, the systematic analysis for the detection and count of L. monocytogenes is not mandatory, but the consumption one or two days after the expiry date must be considered as a likely event, and requires a preventive approach by the producer. Anyway, the prevalence of $43 \%$ is very high and alarming, and, as demonstrated, in thermal abuse storage situations, also if low loads of the pathogen are present at the beginning of the shelf-life, the ability to grow of L. monocytogenes in some of the ingredients (e.g. bean cream) would determine in some case the probable exceed of the threshold limit demanded by EU Reg. 2073/2005 of 100 CFU/g. On the other hand, this limit is, correctly, a conservative threshold bound, necessary especially for the defence of the susceptible categories (elderly, pregnant, young and immunocompromised subjects).

After two days from the expiry date, the product looks like "not fresh" thus the consumption is very improbable by consumers as the spoilage is visible, while after $24 \mathrm{~h}$ from expiry date from a sensorial point of view the product remained acceptable.

The main intervention to be applied is of course the improvement of hygienic practices during sandwiches production that minimize the starting bacterial concentration of each ingredient. This is in agreement with the high prevalence of the pathogen found in a cooked ingredient (bean cream), suggesting a likely post-contamination due to improper handling by operators. The design of a high-risk area that identifies relative barriers to prevent the access of $L$. monocytogenes and the application of correct personal hygiene procedures are additional intervention to reduce the risk. Moreover, adequate cleaning and disinfection programmes could effectively be useful to remove and reduce bacteria from surfaces.

Moreover, apart from the hypothetical suggestion to improve hygienic practices during sandwiches production, different interventions were evaluated for their possible practical application: use of MAP conditioning $\left(30 \% \mathrm{CO}_{2}\right)$, heat treatment before consumption or the combination of the two interventions. From the data obtained, the application of cooking (that is a bactericidal treatment) resulted to have a larger effect in the reduction of potential risk for the consumers, if compared to the MAP packaging alone (that exerts only a bacteriostatic effect); this was expected, due to the weak thermal resistance of L. monocytogenes. Despite the theoretical efficiency of cooking, three critical points should be considered: first, the modifications of sensory characteristics of the sandwiches, that could be hardly accepted by the consumers (a different product formulation could be needed); then, the execution of cooking could be affected by an extra uncertainty source, as it is consumer-dependent. Moreover, the RTE product heat treated would no longer be a RTE so basically the nature and primary image of the product would be upset. Anyway, this intervention could be suggested to specific susceptible population that, although advised to avoid the consumption of specific hazardous categories of food (e.g. RTE, raw milk cheeses, cold smoked salmon, raw meat) sometimes transgress these advices 
(e.g. consumption of contaminated sandwiches in hospitals as reported by Little et al. [18]) and eat these foods. The heating could be a reasonable compromise instead the complete avoid to eat a particular and convenient food such as sandwiches.

Otherwise, MAP conditioning represents an easy implementation in food process, that couples relatively low costs with the possibility of complete control by the food producer. It could be a useful implementation of the production process also considering the possibility of an extension of the shelf life of the product.

To avoid the changing nature of the RTE product, a recommendation could be included in the label, which suggests the avoidance by immunocompromised people.

The application of a stochastic QMRA for pathogens in different foodstuffs represents a useful tool to estimate the actual risk for consumers and is more precise and punctual when a distribution of $r$ values is included. The importance of the application of this approach was recently highlighted by the EFSA BIOHAZ panel, that estimated the listeriosis risk considering both the virulence of L. monocytogenes strains and the host susceptibility (clustering consumers' subpopulations by health status, sex and age).

In the case of complex products like sandwiches, the estimation is particularly tricky due to the presence of ingredients with very different physical-chemical characteristics that cannot be reduced to an "average substrate", coupled with the ubiquitous nature of L. monocytogenes. In the present study the consumption of multi-composed sandwiches, determined a risk in the total population if contamination occurs in bean cream especially while no risk would be present if cream cheese thus enabling to consider the product as safe in that case.

MAP would make the product even safer. The risk would be hypothetically greater if the population was composed by only transplant recipients. Transplant recipients and susceptible in general should be careful and take care, and may need to cook it first, or completely avoid eating this product. As the main source of Listeria monocytogenes is the bean cream an alternative could be the development of new sandwiches for "YOPI people" that do not have this ingredient in their components. 
[1] EFSA and ECDC (European Food Safety Authority and European Centre for Disease Prevention and Control), 2015b, The European Union summary report on trends and sources of zoonoses, zoonotic agents and food-borne outbreaks in 2014, EFSA J., 13(12), 4329.

[2] EFSA and ECDC (European Food Safety Authority and European Centre for Disease Prevention and Control), 2016, The European Union summary report on trends and sources of zoonoses, zoonotic agents and food-borne outbreaks in 2015, EFSA J., 14(12), 4634.

[3] EFSA and ECDC (European Food Safety Authority and European Centre for Disease Prevention and Control), 2017, The European Union summary report on trends and sources of zoonoses, zoonotic agents and food-borne outbreaks in 2016, EFSA J., 15(12), 5077.

[4] Walker S. J., Archer P., Banks J. G., 1990. Growth of Listeria monocytogenes at refrigeration temperatures, J. Appl. Bacteriol. 68,157-162.

[5] Ferreira, V., Wiedmann, M., Teixeira, P., Stasiewicz, M.J., 2014. Listeria monocytogenes Persistence in foodassociated environments: epidemiology, strain characteristics, and implications for public health, J. Food Prot., 1, 150170.

[6] Jackson, K.A., Iwamoto, M., Swerdlow, D., 2010. Pregnancy-associated listeriosis, Epidemiol. Infect., 138, 1503-9.

[7] Silk, B.J., Date, K.A., Jackson, K.A., Pouillot, R., Holt, K.G., Graves, L.M., Ong, K.L., Hurd, S., Meyer, R., Marcus, R., Shiferaw, B., Norton, D.M. Medus, C., Zansky, S.M., Cronquist, A.B., Henao, O.L., Jones, T.F., Vugia, D.J., Farley, M.M., Mahon, B.E., 2012. Invasive listeriosis in the Foodborne Diseases Active Surveillance Network (FoodNet), 2004-2009: further targeted prevention needed for higher-risk groups, Clin. Infect. Dis., 54 Suppl 5, S396404.

[8] EFSA BIOHAZ(EFSA Panel on Biological Hazards), 2018. Listeria monocytogenes contamination of ready-to-eat foods and the risk for human health in the EU, EFSA J., 16(1), 5134.

[9] Farber, J. M., P. Peterkin, 1991. Listeria monocytogenes, a food-borne pathogen, Microbiol. Mol. Biol. Rev. 55, 476-511.

[10] WHO/FAO (World Health Organization, Food and Agriculture Organization of the United Nations), 2004. Risk assessment of Listeria monocytogenes in ready-to-eat foods. Technical Report. Microbiological risk assessment series 5. Food and Agriculture Organization of the United Nations, Rome, Italy. Available at http://www.fao.org/es/esn/food/risk_mra listeria report_en.stm. Accessed on December 21, 2017. 
[11] Cossu, F., Spanu, C., Deidda, S., Mura, E., Casti, D., Pala C., Lamon, S., Spanu, V., Ibba, M., Marrocu, E., Scarano, C., Piana, A., De Santis, E.P.L., 2016, Listeria spp. and Listeria monocytogenes contamination in ready-to-eat sandwiches collected from vending machines. Italian Journal of Food Safety, 5:61-64.

[12] Bouayad, L., Hamdi T-M., 2012. Prevalence of Listeria spp. in ready to eat foods (RTE) from Algiers (Algeria). Food Control, 23:397-399.

[13] Büyükyorük, S., Beyaz, D., GöksoyK E.Ö., Kök,F., Kocak, P., 2012. Microbiological evaluation of ready-to-eat sandwiches served near hospitals and schools. Ankara Üniv. Vet. Fak. Derg., 61:193-198.

[14] Christison, C.A., Lindsay, D., von Holy, A., 2008. Microbiological survey of ready-to-eat foods and associated preparation surfaces in retail delicatessens, Johannesburg, South Africa. Food Control, 19:727-733.

[15] Little, C.L., Barrett, N.J., Grant, K., McLauchlin, J., 2008. Microbiological safety of sandwiches from hospitals and other health care establishments in the United Kingdom with a focus on Listeria monocytogenes and other Listeria species. J. Food Protect., 71:309-318.

[16] Meloni, D., Galluzzo, P., Mureddu, A., Piras, F., Griffiths, M., Mazzette, R., 2009. Listeria monocytogenes in RTE foods marketed in Italy: prevalence and automated EcoRI ribotyping of the isolates. Int. J. Food Microbiol., 129:166173.

[17] Shen, Y., Liu, Y., Zhang, Y., Cripe, J., Conway, W., Meng, J., Hall, G., Bhagwat, A.A, 2006. Isolation and characterization of Listeria monocytogenes isolates from ready-to-eat foods in Florida. Appl. Environ. Microbiol., 72:5073-5076.

[18] Little, C.L., Amar, C.F.L., Awofisayo, A., Grant, K.A., 2012. Hospital-acquired listeriosis associated with sandwiches in the UK: a cause for concern, J. Hosp. Infect., 12:13-18.

[19] Carrasco, E., Pèrez-Rodrìguez, F., Valero, A., Garcìa-Gimeno, R.M., Zurera, G., 2010. Risk assessment and management of Listeria monocytogenes in ready-to-eat lettuce salads. Compr. Rev. Food Sci. Food Saf., 9:498-512.

[20] Mataragas, M., Zwietering , M.H., Skandamis, P.N., Drosinos, E.H., 2010. Quantitative microbiological risk assessment as a tool to obtain useful information for risk managers - Specific application to Listeria monocytogenes and ready-to-eat meat products, Int. J. Food Microbiol., 141 Suppl 1:S170-179.

[21] Nauta, M.J., Litman, S., Barker, G.C., Carlin, F., 2003. A retail and consumer phase model for exposure assessment of Bacillus cereus. Int. J. Food Microbiol., 83:205-218.

[22] Stals, A., Jacxsens, L., Baert, L., Van Coillie, E., Uyttendaele, M., 2015. A quantitative exposure model simulating human norovirus transmission during preparation of deli sandwiches. Int. J. Food Microbiol., 196:126-136.

[23] Association Francaise de Normalisation. Enumeration of Listeria monocytogenes and Listeria spp. AFNOR BRD $07 / 05-09 / 01$. 
[24] Bradley, R.L.,Vanderwarn, M.A., 2001. Determination of moisture in cheese and cheese products. J. AOAC Int., $84: 570-592$

[25] Pearson, D., 1973. Laboratory Techniques in Food Analysis. Butterworths \& Co. Publishers, London, pp. $201-202$.

[26] Tormo, M., Izco, J.M., 2004. Alternative reversed-phase high-performance liquid chromatography method to analyse organic acids in dairy products. J. Chromatog. A, 1033:305-310.

[27] ICH Topic Q 2 (R1),1995. Validation of Analytical Procedures: Note for guidance on validation of analytical procedures: text and methodology (CPMP/ICH/381/95). European Medicines Agency (Emea).

[28] Nauta, M.J., 2008. The Modular Process Risk Model (MPRM): a structured approach to food chain exposure assessment. In: Schaffner, D.W. (Ed.), Microbial Risk Analysis of Foods. ASM press, Washington, D.C., pp. 99-136.

[29] Roccato, A.,Uyttendaele, M., Membré, J.M., 2017. Analysis of domestic refrigerator temperatures and home storage time distributions for shelf-life studies and food safety risk assessment, Food Res. Int., 96:171-181.

[30] James, S.J, Evans, J., James, C., 2008. A review of the performance of domestic refrigerators. J. Food Eng., 87:210.

[31] FAO-WHO (Food and Agriculture Organization-World Health Organization), 2001. Joint FAO/WHO expert consultation on risk assessment of microbiological hazards in food. Risk characterization of Salmonella spp. in eggs and broiler chickens and Listeria monocyotgenes in ready-to-eat foods, FAO Food and Nutrition Paper n ${ }^{\circ} 72$, FAO, Rome, Italy, pp. 26-27.

[32] Pouillot R., Hoelzer K., Chen Y., Dennis S.B., 2015. Listeria monocytogenes dose response revisited-incorporating adjustments for variability in strain virulence and host susceptibility. Risk Analysis, 35:90-108.

$$
\text { Ministero }
$$

della

Salute,

2016.

http://www.trapianti.salute.gov.it/cnt/cntPrimoPianoDett.jsp?area=cntgenerale\&menu=menuPrincipale\&id=359.

Accessed on December 21,2017.

[34] Shi, Y., Tang, J., Yue, T., Rasco, B., Wang, S., 2015. Pasteurizing cold smoked salmon (Oncorhynchus nerka): thermal inactivation kinetics of Listeria monocytogenes and Listeria innocua, J. Aquat. Food Prod. Tech., 24:712-722. [35] Rørvik, L.M.,. Caugant, D.A., Yndestad, M., 1995. Contamination pattern of Listeria monocytogenes and other Listeria spp. in a salmon slaughterhouse and smoked salmon processing plant. Int. J. Food Microbiol., 25:19-27.

[36] Lokerse, R.F.A., Maslowska-Corker, K.A., van de Wardt, L.C., Wijtzes T., 2016. Growth capacity of Listeria monocytogenes in ingredients of ready-toeat salads, Food Control, 60:338-345.

[37] Mena, C., Almeida, G., Carneiro, L., Teixeira, P., Hogg, T., Gibbs, P.A., 2004. Incidence of Listeria monocytogenes in different food products commercialized in Portugal, Food Microbiol., 2:213-216. 
[38] Di Pinto, A., Novello, L., Montemurro, F., Bonerba, E., Tantillo, G., 2010, Occurrence of Listeria monocytogenes in ready-to-eat foods from supermarkets in Southern Italy, New Microbiologica, 33:249-252.

[39] Friedrich, L., Sirò, I., Dalmadi, I., Horvàth, K., Àgoston, R., Balla, Cs., 2008. Influence of various preservatives on the quality of minced beef under modified atmosphere at chilled storage, Meat Sci., 79:332-343.

[40] Stella, S., Tirloni, E., Ripamonti, B., Lamanuzzi, F., Cattaneo, P., 2014, Quality and hygiene of beef burgers in relation to the addition of sodium ascorbate, sodium citrate and sodium acetate, Int. J. Food Sci. Technol., 49:10121019.

[41] http://www.salute.gov.it/portale/news/p3 221111 1.jsp?lingua=italiano\&menu=notizie\&p=dalministero \&id=2440. Accessed on December 21, 2017. 


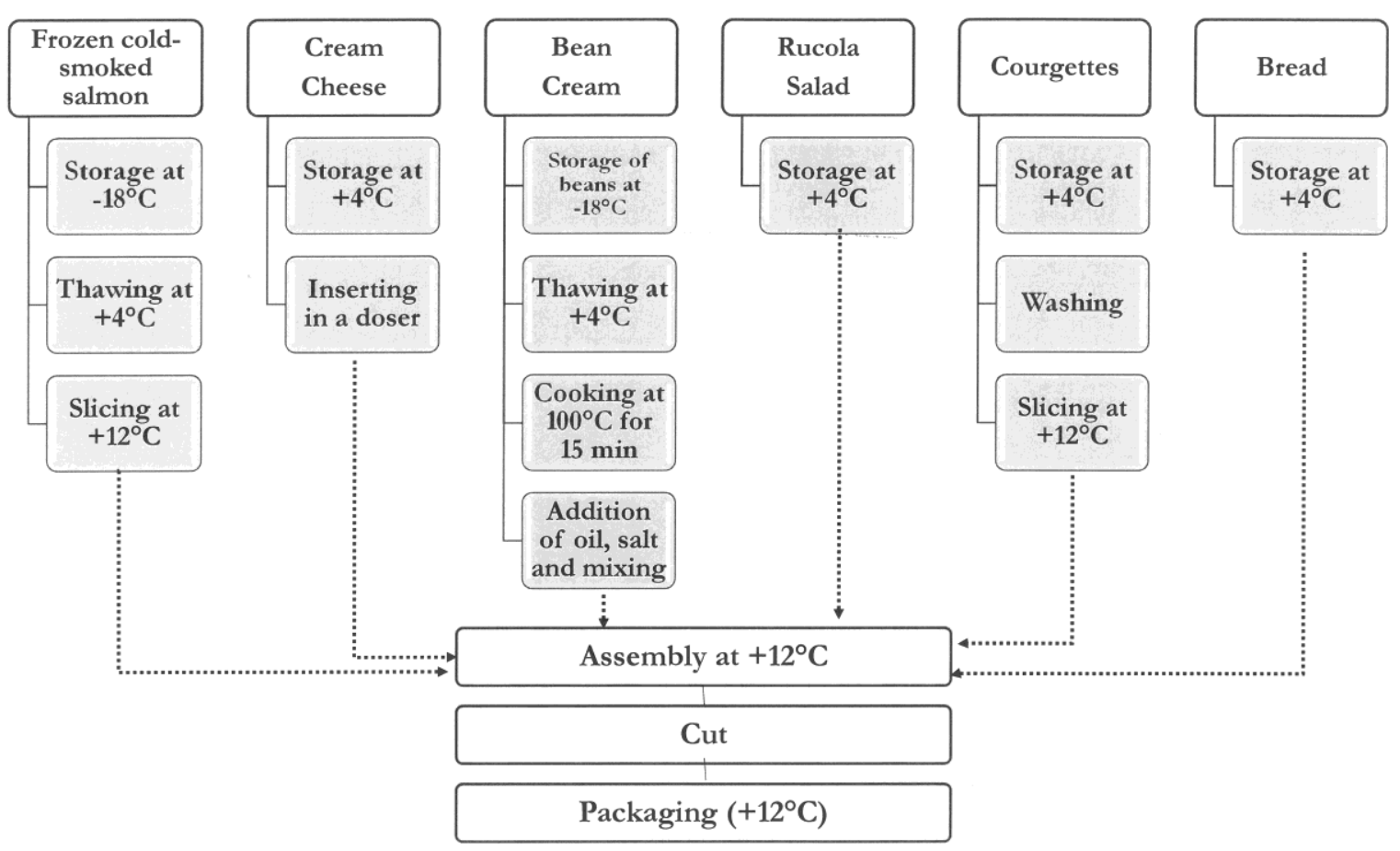

Figure 1. Flowchart of the production process of sandwiches. 


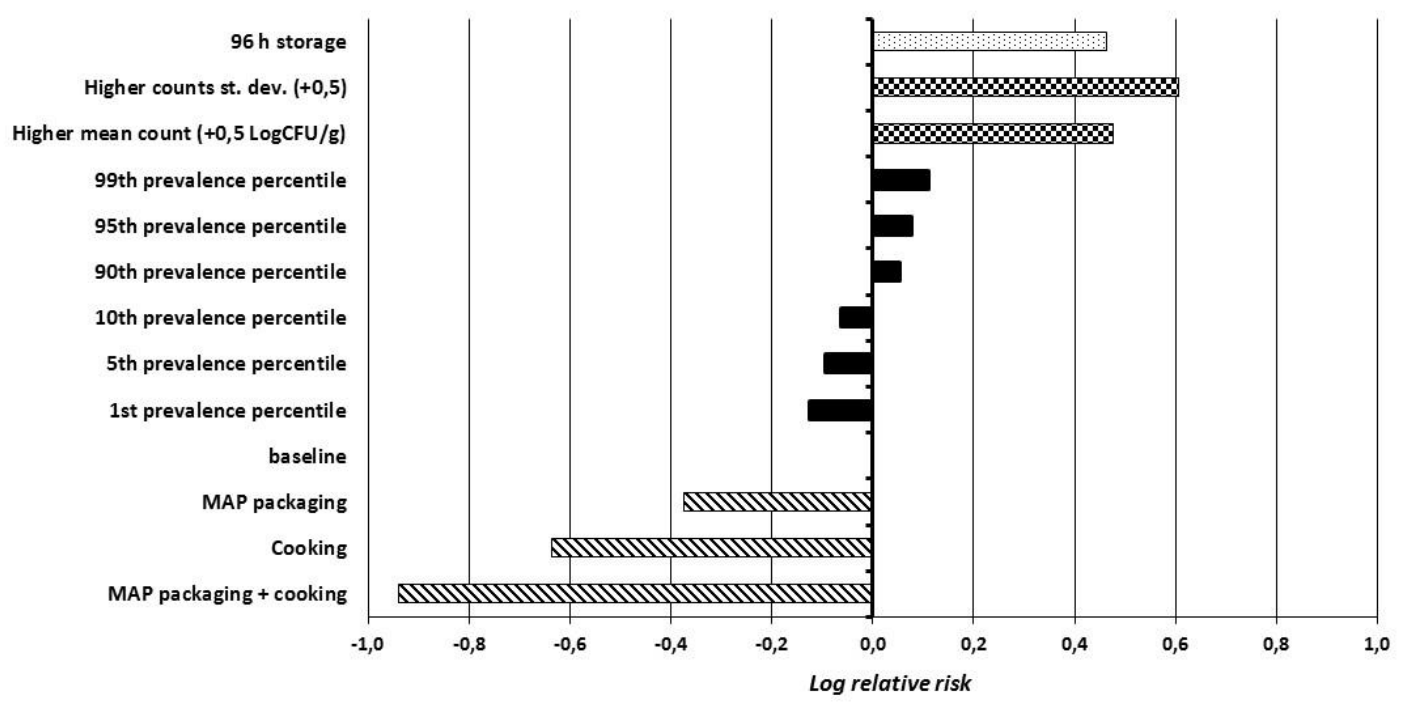

Figure 2. Log Relative Risk calculated mimicking a contamination by L. monocytogenes in bean cream (worst case scenario) in the total population by using lognormal Poisson distribution of $r$ values. 
Tables

Table 1. Overview of variables and parameters in the exposure assessment model.

\begin{tabular}{|c|c|c|c|c|}
\hline $\begin{array}{l}\text { Variable/ } \\
\text { paramer }\end{array}$ & Description & $\begin{array}{c}\text { Value/Excel-@ Risk model } \\
\text { equation }\end{array}$ & Unit & Source \\
\hline $\mathrm{N}_{\text {tot }}$ & $\begin{array}{l}\text { Total } n^{\circ} \text { of analyzed } \\
\text { samples }\end{array}$ & 100 & $\mathrm{~N}$ & User input \\
\hline $\mathrm{N}_{\text {cont }}$ & $\mathrm{N}^{\circ}$ of contaminated samples & 43 & $\mathrm{~N}$ & User input \\
\hline $\mathrm{P}$ & Prevalence & $\mathrm{N}_{\text {tot }} / \mathrm{N}_{\text {cont }} * 100$ & $\%$ & Calculated \\
\hline $\mathrm{C}_{\text {mean }}$ & $\begin{array}{l}\text { Mean bacterial } \\
\text { concentration }\end{array}$ & $=$ AVERAGE $($ Log counts $)$ & $\mathrm{Log}$ CFU/g & $\begin{array}{l}\text { Calculated from } \\
\text { our data }\end{array}$ \\
\hline $\mathrm{C}_{\mathrm{SD}}$ & Standard deviation of counts & $=\mathrm{STDEV}(\mathrm{Log}$ counts $)$ & No units & $\begin{array}{l}\text { Calculated from } \\
\text { our data }\end{array}$ \\
\hline $\mathrm{C}_{0}$ & $\begin{array}{l}\text { Initial L. monocytogenes } \\
\text { concentration }\end{array}$ & $=$ RiskNormal $\left(\mathrm{C}_{\text {mean }} ; \mathrm{C}_{\mathrm{SD}}\right)$ & Log CFU/g & Calculated \\
\hline Temp $_{\text {stor }}$ & Storage temperature & $=$ RiskTriang $(4 ; 6 ; 10)$ & ${ }^{\circ} \mathrm{C}$ & User input \\
\hline$\Delta \mathrm{C}_{\text {bean }}$ & $\begin{array}{l}\text { Log CFU increase }(72 \mathrm{~h})- \\
\text { Bean cream scenario }\end{array}$ & $=0,3557 *$ Temp $_{\text {Stor }}+0,2486$ & $\Delta \log$ & $\begin{array}{l}\text { Obtained from } \\
\text { challenge test }\end{array}$ \\
\hline$\Delta \mathrm{C}_{\text {cheese }}$ & $\begin{array}{l}\text { Log CFU increase }(72 \mathrm{~h})- \\
\text { Cream cheese scenario }\end{array}$ & $=0,0064 * \mathrm{Temp}_{\text {Stor }}+0,5671$ & $\mathrm{Log} \mathrm{CFU} / \mathrm{g}$ & $\begin{array}{l}\text { Obtained from } \\
\text { challenge test }\end{array}$ \\
\hline $\mathrm{C}_{\text {final }}$ & $\begin{array}{l}\text { L. monocytogenes } \\
\text { concentration after storage }\end{array}$ & $=\mathrm{C}_{0}+\Delta \mathrm{C}$ & $g$ & Calculated \\
\hline $\mathrm{W}$ & Weight of the serving & 210 & $\mathrm{~g}$ & User input \\
\hline $\mathrm{D}$ & $\begin{array}{l}\text { Ingested L. monocytogenes } \\
\text { dose }\end{array}$ & $=\operatorname{POWER}\left(10 ; \mathrm{C}_{\text {Final }}\right) *$ & CFU/serving & Calculated \\
\hline
\end{tabular}

Table 2. Parameters and variables used for the dose-response models.

\begin{tabular}{|c|c|c|c|c|c|}
\hline Subpopulation & $\begin{array}{c}\begin{array}{c}\text { Fraction of } \\
\text { total } \\
\text { population } \\
(\%)\end{array} \\
\text { (\%) }\end{array}$ & $\begin{array}{c}\text { Fixed } \log r \\
\text { yalue (model } \\
\text { 1) }\end{array}$ & $\begin{array}{c}\text { Mean } \log r \\
\text { value with } \\
\text { variable } r \text {, } \\
r_{\text {spec }}(\text { model } \\
\text { 2) }\end{array}$ & $\begin{array}{l}\text { Random } \log r \\
\text { value (per } \\
\text { serving) } \log r_{\mathrm{s}} \\
\text { for each } \\
\text { subpopulation }\end{array}$ & $\begin{array}{c}\mathbf{P}_{\text {ill, }}, \\
\text { subpopulation }\end{array}$ \\
\hline healthy & 76.71 & -13.63 & -14.11 & \multirow{3}{*}{$\begin{array}{c}\text { RiskNormal }\left(\mathrm{r}_{\text {spec }}\right. \\
1.62)\end{array}$} & \multirow{3}{*}{$\begin{array}{c}\mathrm{P}_{\mathrm{ill}}=1-\mathrm{EXP}(- \\
\left.\mathrm{r}_{\mathrm{s}} * \mathrm{D}\right)(* *)\end{array}$} \\
\hline transplant & 0.0062 & -9.24 & -11.51 & & \\
\hline susceptible & $\begin{array}{c}23.28 \text { (split up } \\
\text { as in Pouillot et } \\
\text { al 2015)* }\end{array}$ & -11.97 & $\begin{array}{c}\text { See table II } \\
\text { from Pouillot } \\
\text { et al., } 2015 \\
(*)\end{array}$ & & \\
\hline
\end{tabular}

(*) Different susceptible subpopulations consist of $\mathrm{N}_{\text {subpop }}$ individuals per subpopulation in a total population of 20.000 consumers and have $\log r_{\text {subpop }}$ values as given by Pouillot et al 2015; from this, a random $r_{\text {spec }}$ value is sampled using a RiskDiscrete $\left(\mathrm{r}_{\text {subpop }} ; \mathrm{N}_{\text {subpop }}\right)$ distribution.

(**) The expected number of cases per subpopulation is calculated as RiskMean $\left(\mathrm{P}_{\mathrm{ill}}\right.$, subpopulation $) \times \mathrm{Ns} \times \mathrm{P}$. 
Table 3. Parameters and variables used in the alternative scenarios applied for the uncertainty analysis and the evaluation of the interventions.

\begin{tabular}{|c|c|c|c|c|c|}
\hline Phase & $\begin{array}{c}\text { Variable/pa } \\
\text { ramer }\end{array}$ & Description & Value & Unit & Source \\
\hline \multirow[t]{5}{*}{$\begin{array}{l}\text { Uncertainty } \\
\text { analysis }\end{array}$} & $\overline{\mathrm{P}_{\text {Stoc }}}$ & Prevalence (stochastic) & $\begin{array}{l}=\operatorname{RiskBeta}\left(\mathrm{N}_{\text {cont }}+1 ; \mathrm{N}_{\text {tot }^{-}}\right. \\
\left.\mathrm{N}_{\text {cont }}+1\right)\end{array}$ & Percent & Calculated \\
\hline & High $\mathrm{C}_{\text {Mean }}$ & $\begin{array}{l}\text { Mean bacterial } \\
\text { concentration }\end{array}$ & $=$ Average $($ Log counts $)+0.5$ & Log CFU/g & Calculated \\
\hline & High $\mathrm{C}_{\mathrm{SD}}$ & $\begin{array}{l}\text { Standard deviation of } \\
\text { bacterial counts }\end{array}$ & $=\mathrm{STDEV}(\mathrm{Lo}$ & No units & Calculated \\
\hline & $96 \mathrm{~h} \Delta \mathrm{C}_{\text {bean }}$ & Log CFU increase (96 h) & $=0,2229 * \mathrm{~T}$ & $\Delta \mathrm{Lc}$ & $\begin{array}{l}\text { This study } \\
\text { (data from } \\
\text { challenge } \\
\text { test) }\end{array}$ \\
\hline & $96 \mathrm{~h} \Delta \mathrm{C}_{\text {cheese }}$ & Log CFU increase (96 h) & $=0,0286 * \mathrm{~T}$ & & $\begin{array}{l}\text { This study } \\
\text { (data from } \\
\text { challenge } \\
\text { test) }\end{array}$ \\
\hline \multirow[t]{7}{*}{$\begin{array}{l}\text { Intervention } \\
\mathrm{s}\end{array}$} & $\overline{M A P} \Delta \mathrm{C}_{\text {bean }}$ & Log CFU increase (MAP) & $=0,2404^{*}$ & $\begin{array}{l}\Delta \log \\
\mathrm{CFU} / \mathrm{g}\end{array}$ & $\begin{array}{l}\text { This study } \\
\text { (data from } \\
\text { challenge } \\
\text { test) }\end{array}$ \\
\hline & $\begin{array}{l}\mathrm{MAP} \Delta \mathrm{C}_{\text {chees }} \\
\mathrm{e}\end{array}$ & Log CFU increase (MAP) & 5314 & $\begin{array}{l}\Delta \mathrm{Log} \\
\mathrm{CFU} / \mathrm{g}\end{array}$ & $\begin{array}{l}\text { This study } \\
\text { (data from } \\
\text { challenge } \\
\text { test) }\end{array}$ \\
\hline & $\mathrm{D}_{\text {temp }}$ & $\begin{array}{l}\text { D value for different } \\
\text { temperatures }\end{array}$ & See T & Min. & $\begin{array}{l}\text { Shi et al., } \\
2015\end{array}$ \\
\hline & $\mathrm{D}_{\text {val }}$ & Estimated D Value & $=$ RiskDuniform $\left(D_{\text {temp }}\right)$ & Min. & Calculated \\
\hline & Time & Cooking time & $=$ RiskTriang $(1 ; 2 ; 4)$ & Min. & Calculated \\
\hline & Cook $\Delta \mathrm{C}$ & Log reduction after cooking & $=$ Time $/ \mathrm{D}_{\mathrm{val}}$ & $\mathrm{Log}$ CFU/g & Calculated \\
\hline & CookC $_{\text {final }}$ & Log count after cooking & $=\mathrm{C}_{\text {final }}-\operatorname{Cook} \Delta \mathrm{C}$ & Log CFU/g & Calculated \\
\hline
\end{tabular}

Table 4. Mean D values obtained from literature for L. monocytogenes (Shi et al., 2015).

\begin{tabular}{cc}
\hline $\mathbf{T}\left({ }^{\circ} \mathbf{C}\right)$ & D value \\
\hline 58 & 11.2 \\
\hline 60 & 3.8 \\
\hline 62 & 2.2 \\
\hline 64 & 1.0 \\
\hline 66 & 0.5 \\
\hline
\end{tabular}

Table 5. Physical-chemical characterization of each ingredient of the sandwiches (average of 5 samples analysed \pm sd).

\begin{tabular}{cccccccc}
\hline & & & & & \multicolumn{2}{c}{ Organic acids water phase (ppm) } \\
\cline { 5 - 8 } & $\mathbf{a}_{\mathbf{w}}$ & $\mathbf{p H}$ & $\begin{array}{c}\text { Moisture } \\
\mathbf{( \% )}\end{array}$ & $\begin{array}{c}\text { Salt } \\
\mathbf{( \% )}\end{array}$ & $\begin{array}{c}\text { Lactic } \\
\text { acid }\end{array}$ & $\begin{array}{c}\text { Citric } \\
\text { acid }\end{array}$ & $\begin{array}{c}\text { Acetic } \\
\text { acid }\end{array}$ \\
\hline Salmon & $0.96 \pm 0.00$ & $6.22 \pm 0.12$ & $67.91 \pm 1.03$ & $2.89 \pm 0.59$ & $7115 \pm 120$ & $<\mathrm{LOQ}$ & $567 \pm 88$ \\
\hline Green salad & $0.99 \pm 0.00$ & $6.59 \pm 0.12$ & $93.11 \pm 1.09$ & $0.21 \pm 0.06$ & $<\mathrm{LOQ}$ & $<\mathrm{LOQ}$ & $1888 \pm 1549$ \\
\hline Courgettes & $0.99 \pm 0.00$ & $6.63 \pm 0.04$ & $95.19 \pm 0.41$ & $0.14 \pm 0.02$ & $1891 \pm 1227$ & $155 \pm 113$ & $2361 \pm 856$ \\
\hline Bean cream & $0.98 \pm 0.01$ & $7.00 \pm 0.10$ & $79.41 \pm 1.95$ & $1.94 \pm 0.76$ & $636 \pm 357$ & $2729 \pm 540$ & $377 \pm 43$ \\
\hline Cream cheese & $0.98 \pm 0.01$ & $4.47 \pm 0.02$ & $69.09 \pm 2.21$ & $0.70 \pm 0.11$ & $8388 \pm 162$ & $776 \pm 99$ & $831 \pm 278$ \\
\hline Bread & $0.95 \pm 0.01$ & $5.61 \pm 0.16$ & $36.62 \pm 0.22$ & $1.08 \pm 0.01$ & $<\mathrm{LOQ}$ & $716 \pm 139$ & $<\mathrm{LOQ}$ \\
\hline
\end{tabular}


Table 6. Log increases of L. monocytogenes $(\Delta \mathrm{C})$ after $72 \mathrm{~h}$ of storage at three different temperatures in each ingredient of the sandwiches. Duplicate results are shown of the difference between the concentrations (in Log CFU/g) at the start of the challenge tests and after $72 \mathrm{~h}$.

\begin{tabular}{cccccc}
\hline & Courgette/salad & Salmon & Bean cream & $\begin{array}{c}\text { Cream } \\
\text { cheese }\end{array}$ & Bread \\
\hline $4^{\circ} \mathrm{C}$ & $1.95-2.12$ & $0.64-0.84$ & $2.09-2.11$ & $0.55-0.63$ & $0.81-0.88$ \\
\hline $6^{\circ} \mathrm{C}$ & $2.09-2.25$ & $0.82-0.88$ & $2.75-3.00$ & $0.57-0.68$ & $1.00-1.27$ \\
\hline $10^{\circ} \mathrm{C}$ & $3.28-3.31$ & $2.00-2.14$ & $3.85-3.85$ & $0.51-0.74$ & $1.51-1.53$ \\
\hline
\end{tabular}

Table 7. Expected number of cases in different scenarios for 20.000 servings by considering total population by using a fixed value of $\mathrm{r}$ (FAO, 2004).

\begin{tabular}{ccccccccc}
\hline & \multicolumn{3}{c}{ Worst case scenario (growth in bean cream) } & \multicolumn{3}{c}{ Best case scenario (growth in cream cheese) } \\
\cline { 2 - 9 } Expected number of cases & Healthy & Susceptible & Transplanted & $\begin{array}{c}\text { Total } \\
\text { population }\end{array}$ & Healthy & $\begin{array}{c}\text { Susceptible } \\
\text { Transplanted } \\
\text { population }\end{array}$ \\
\hline Baseline & 0.002 & 0.098 & 52 & 0.028 & $<0.001$ & 0.001 & 0.286 & $<0.001$ \\
\hline Low Prevalence 1\% & 0.001 & 0.073 & 39 & 0.021 & $<0.001$ & $<0.001$ & 0.213 & $<0.001$ \\
\hline Low Prevalence 5\% & 0.002 & 0.080 & 42 & 0.023 & $<0.001$ & $<0.001$ & 0.233 & $<0.001$ \\
\hline Low Prevalence 10\% & 0.002 & 0.084 & 45 & 0.024 & $<0.001$ & $<0.001$ & 0.246 & $<0.001$ \\
\hline High Prevalence 90\% & 0.002 & 0.112 & 59 & 0.032 & $<0.001$ & 0.001 & 0.326 & $<0.001$ \\
\hline High Prevalence 95\% & 0.002 & 0.116 & 62 & 0.033 & $<0.001$ & 0.001 & 0.340 & $<0.001$ \\
\hline High Prevalence 99\% & 0.003 & 0.125 & 67 & 0.036 & $<0.001$ & 0.001 & 0.366 & $<0.001$ \\
\hline+ +.5 Log mean count & 0.007 & 0.309 & 156 & -0.087 & $<0.001$ & 0.002 & 1 & $<0.001$ \\
\hline + 0.5 Log ST.DEV. & 0.016 & 1 & 210 & 0.193 & $<0.001$ & 0.004 & 2 & 0.001 \\
\hline Storage 96 h & 0.006 & 0.289 & 151 & 0.082 & $<0.001$ & $<0.001$ & 0.348 & $<0.001$ \\
\hline
\end{tabular}

Table 8. Expected number of cases in different scenarios for 20.000 servings by considering total population by using a variable $r$ value (Pouillot et al., 2015).

\begin{tabular}{|c|c|c|c|c|c|c|c|c|}
\hline \multirow[b]{2}{*}{ Expected number of cases } & \multicolumn{4}{|c|}{ Worst case scenario (growth in bean cream) } & \multicolumn{4}{|c|}{ Best case scenario (growth in cream cheese) } \\
\hline & Healthy & & Transplanted & $\begin{array}{c}\text { Total } \\
\text { population }\end{array}$ & Healthy & Susceptible & Transplanted & $\begin{array}{c}\text { Total } \\
\text { population }\end{array}$ \\
\hline Baseline & 1 & 9 & 45 & 3 & 0.004 & 0.145 & 1 & 0.037 \\
\hline Low Prevalence $1 \%$ & 12 & 7 & 33 & 2 & 0.003 & 0.108 & 1 & 0.028 \\
\hline Low Prevalence 5\% & 1 & 7 & 37 & 2 & 0.003 & 0.118 & 1 & 0.030 \\
\hline Low Prevalence $10 \%$ & 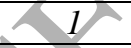 & 8 & 39 & 3 & 0.003 & 0.125 & 1 & 0.032 \\
\hline High Prevalence $90 \%$ & 1 & 10 & 51 & 3 & 0.005 & 0.165 & 1 & 0.042 \\
\hline High Prevalence $95 \%$ & $1^{\prime}$ & 11 & 53 & 4 & 0.005 & 0.172 & 1 & 0.044 \\
\hline High Prevalence $99 \%$ & 1 & 12 & 58 & 4 & 0.005 & 0.185 & 1 & 0.047 \\
\hline+0.5 Log mean count & 1 & 21 & 95 & 6 & 0.009 & 0.339 & 3 & 0.086 \\
\hline + 0.5 Log ST.DEV. & 2 & 24 & 86 & 7 & 0.016 & 1 & 3 & 0.203 \\
\hline Storage $96 \mathrm{~h}$ & 1 & 25 & 101 & 7 & 0.005 & 0.231 & 1 & 0.058 \\
\hline
\end{tabular}


Table 9. Expected number of cases when applying three interventions considered in worst-case scenario and best-case scenario by using a fixed value of $\mathrm{r}$ (FAO, 2004).

\begin{tabular}{|c|c|c|c|c|c|c|c|c|}
\hline \multirow[b]{2}{*}{ Expected number of cases } & \multicolumn{4}{|c|}{ Worst case scenario (growth in bean cream) } & \multicolumn{4}{|c|}{ Best case scenario (growth in cream cheese) } \\
\hline & Healthy & Susceptible & Transplant & $\begin{array}{c}\text { Total } \\
\text { population }\end{array}$ & Healthy & Susceptible & Transplant & $\begin{array}{c}\text { Total } \\
\text { population }\end{array}$ \\
\hline Baseline & 0.002 & 0.098 & 52 & 0.028 & $<0.001$ & 0.001 & 0.286 & $<0.001$ \\
\hline MAP $\left(30 \% \mathrm{CO}_{2}\right)$ & $<0.001$ & 0.029 & 16 & 0.008 & $<0.001$ & $<0.001$ & 0.070 & $<0.001$ \\
\hline Cooking & $<0.001$ & 0.020 & 11 & 0.006 & $<0.001$ & $<0.001$ & 0.057 & $<0.001$ \\
\hline MAP $\left(30 \mathrm{CO}_{2}+\right.$ cooking $)$ & $<0.001$ & 0.006 & 3 & 0.002 & $<0.001$ & $<0.001$ & 0.014 & $<0.001$ \\
\hline
\end{tabular}

Table 10. Expected number of cases when applying three interventions considered in worst-case scenario and best-case scenario by using a variable $\mathrm{r}$ value (Pouillot et al., 2015).

\begin{tabular}{|c|c|c|c|c|c|c|c|c|}
\hline \multirow[b]{2}{*}{ Expected number of cases } & \multicolumn{4}{|c|}{ Worst case scenario (growth in bean cream) } & \multicolumn{4}{|c|}{ Best case scenario (growth in cream cheese) } \\
\hline & Healthy & Susceptible & Transplant & $\begin{array}{c}\text { Total } \\
\text { population }\end{array}$ & Healthy & usceptible & Transplant & $\begin{array}{c}\text { Total } \\
\text { population }\end{array}$ \\
\hline Baseline & $\bar{l}$ & 9 & 45 & 3 & 0.004 & 0.145 & $\bar{l}$ & 0.037 \\
\hline MAP $\left(30 \% \mathrm{CO}_{2}\right)$ & 0.220 & 4 & 22 & 1 & 0.001 & 0.037 & 0.221 & 0.009 \\
\hline Cooking & 0.122 & 3 & 12 & 1 & $<0.001$ & 0.033 & 0.185 & 0.008 \\
\hline MAP (30 $\mathrm{CO}_{2}+$ cooking) & 0.039 & 1 & 6 & 0.289 & $<0.001$ & 0.008 & 0.047 & 0.002 \\
\hline
\end{tabular}

